\title{
Cleft lip and palate, pili torti, malformed ears, partial syndactyly of fingers and toes, and mental retardation: a new syndrome?
}

\author{
J ZLOTOGORA*, Y ZILBERMAN†, A TENENBAUM‡, AND M R WEXLER \\ From the Departments of Human Genetics*, and Plastic and Maxillofacial Surgery\$, Hadassah Medical \\ Center; the Department of Orthodontics, School of Dental Medicine, Hebrew University; and $\ddagger$ the Jerusalem \\ Community Center for Child and Family Development, Jerusalem, Israel.
}

SUMmaRY Two sibs with a syndrome including cleft lip and palate, sparse scalp hair, malformed protruding ears, and partial syndactyly of the fingers and toes are reported. The older child also has mental retardation and pili torti. This syndrome is most probably inherited as an autosomal recessive disorder.

Cleft lip and palate or both is found in more than 150 syndromes, ${ }^{1}$ but many patients with multiple malformations including cleft lip/palate cannot at present be classified. Recently, we examined two sibs with a syndrome including cleft lip and palate, sparse scalp hair, malformed protruding ears, and partial syndactyly of the fingers and toes.

\section{Case reports}

The parents were first cousin Moslem Arabs, The two children reported here were born of the seventh and eighth pregnancies when the mother was 35 and 37 years old respectively and the father 37 and 39 years old. Both pregnancies were normal and the mother did not take any medication. Seven children, born before the two reported here had no malformations. There were two males and five females and one of them, a male twin of an unlike sexed pair, died suddenly in infancy.

The proband was first examined at the age of four months when referred for correction of his cleft lip. The child appeared retarded for his age and there was complete head lag. The head circumference was normal for age, the hair was sparse, the ears were protruding and malformed, and micrognathia and bilateral cleft lip and palate were evident (figs 1 and 2 ). There was partial syndactyly of the left third and fourth fingers and the third and fourth toes on both feet. A simian line was present on the left palm and a Sydney line on the right. The karyotype was normal $46, X Y$.

Received for publication 11 September 1985.

Revised version accepted for publication 10 February 1986.
The mother became pregnant again at the age of 37 years but did not contact us. The child, a girl, was referred at the age of four months for correction of a cleft lip. The resemblance of the girl to the proband was striking (table). She had the same type of hair, malformed protruding ears, left cleft lip, and cleft palate. In both hands partial syndactyly of the third and fourth fingers as well as Sydney lines were noted. Partial syndactyly of the third and fourth toes was also present. The child died suddenly at the age

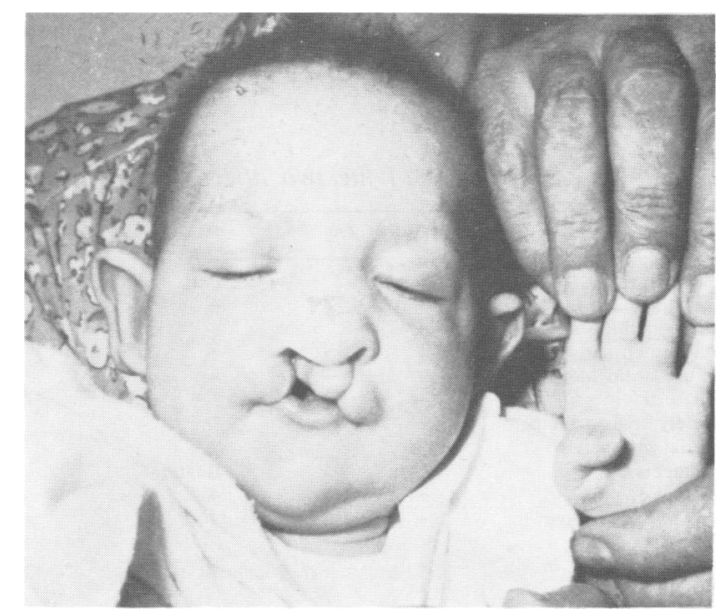

FIG 1 The proband aged four months after partial correction of left cleft lip. Note partial syndactyly of 3rd and 4th fingers and simian line. 


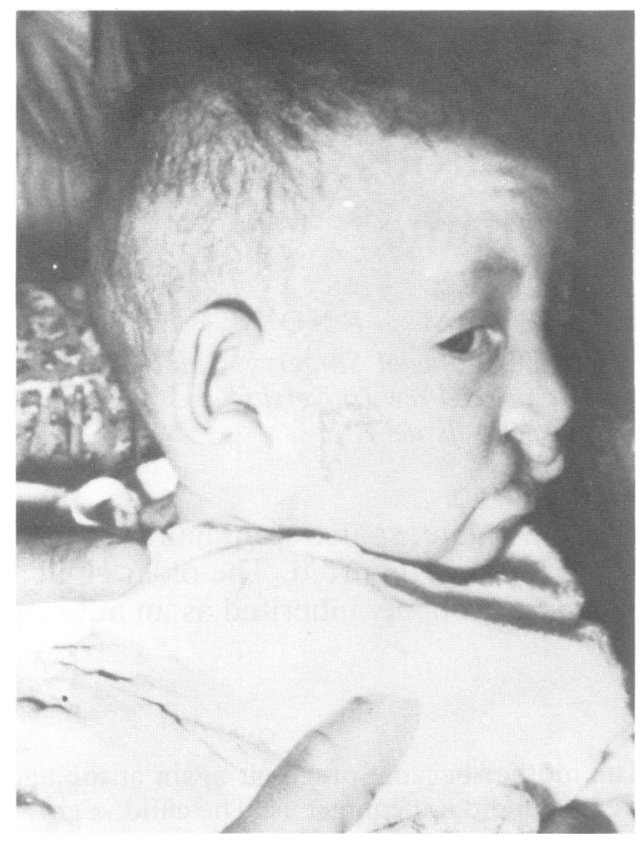

FIG 2 The proband aged four months. Note the abnormal ear.

of eight months; on that day she was feverish and an upper respiratory infection was diagnosed by her family doctor.

The proband was re-examined at the age of three and a half years. His motor development has been slow; he was performing at approximately a 24 month level and was only speaking very few words. The child was, like his father, relatively tall (height 80 th centile), and his weight (15th centile) and head

TABLE Clinical features of the two affected sibs.

\begin{tabular}{lll}
\hline & Patient 1 & Patient 2 \\
\hline Cleft lip & Bilateral & Left \\
Cleft palate & + & + \\
Micrognathia & + & + \\
Malformed, protruding ears & + & + \\
Sparse scalp hair & + & + \\
Pili torti & + & $?$ \\
Widely spaced teeth & + & $?$ \\
Partial syndactyly & & Bilateral \\
$\quad$ Fingers 3, 4 & Left & + \\
$\quad$ Toes 3, 4 & + & + \\
Simian/Sydney line & + & + \\
Severe head lag in & & \\
$\quad$ infancy & + & $?$ \\
Mental retardation & & Female \\
Sex & + & Not done \\
Karyotype & Male &
\end{tabular}

circumference (10th centile) were normal. The inner $\stackrel{+}{\Rightarrow}$ and outer canthal distances were normal for age $\overrightarrow{\vec{s}}$ (80th centile) but relatively large for the heado circumference. There was an antimongoloid slant to흠 the eyes. The ears were protruding and malformed. $\overline{\bar{D}}$. An additional finding was widely spaced nipples $\mathbb{\varnothing}$ ( $>97$ th centile) with a normal chest circumference (10th centile). The scrotum was hypoplastic and the ${ }^{\mathcal{S}}$ testes were in the inguinal canal. A transverse crease $\vec{O}$ was present on both palms, simian on the left and $\overrightarrow{-}$ Sydney on the right. Partial syndactyly of the third and fourth fingers of the left hand and toes of both $\overline{3}$. feet was also found. The hair was sparse and theo outer part of the eyebrows was almost absent. The lashes were normal. On microscopical examinationic (fig 3) the hair was twisted and pili torti wasi diagnosed. The teeth were widely spaced and much ${ }^{-}$ caries was present. The skin and the nails were normal.

\section{Discussion}

Both children were affected with a similar syn $\vec{\oplus}$ drome. Their parents are first cousins and healthy.

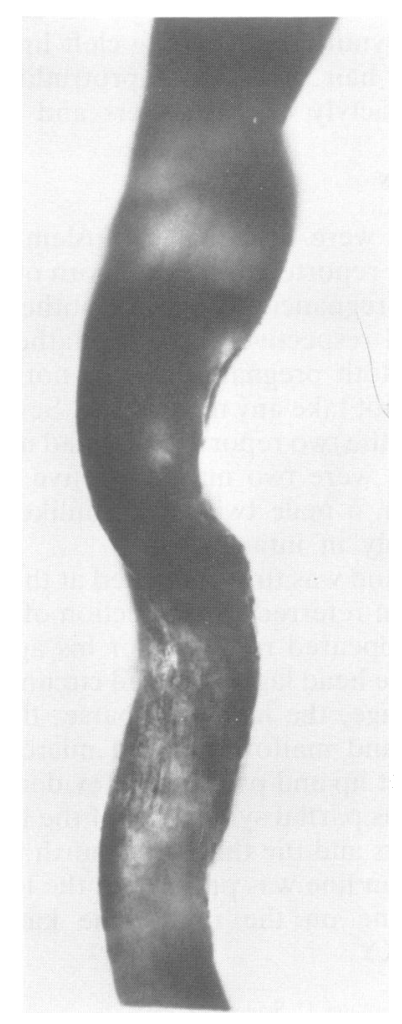

FIG 3 Twisted hair. 
The karyotype of the boy was normal and therefore this syndrome is likely to be inherited as an autosomal recessive disorder. From a review of published reports on syndromes including cleft lip or cleft palate or both, we were unable to find a syndrome similar to the one described here.

Pili torti is characterised by twisted hairs and is often present with other ectodermal signs, mainly involvement of the teeth. Pili torti has been reported as an autosomal dominant entity or as part of many different syndromes. ${ }^{2}$ Wiedemann ${ }^{3}$ reported an inbred family where three out of five children presented with pili torti, sparse eyebrows and lashes, tooth anomalies including severe crown hypoplasia and delayed atypical eruption of permanent teeth, as well as thick yellowish nails. The skin was dry and hyperkeratosis was present. In addition, syndactyly of both fingers and toes to variable degrees was also present in the children as well as transverse creases on both palms. The palate was highly arched and growth and psychomotor development were normal. Many of the signs in the children reported by Wiedemann ${ }^{3}$ were similar to those found in the children in this report, including pili torti, syndactyly, and transverse crease on the palms, but other signs differ, including mental development, lip and palate involvement, and other ectodermal signs in nails, teeth, and skin. Both syndromes are probably inherited as autosomal recessive disorders.

Recognition of further affected children as well as follow up of the child presented here will help to delineate this syndrome better.

\section{References}

${ }^{1}$ Cohen MM. Syndromes with cleft lip and cleft palate. Cleft Palate J 1978;15:306-28.

2 Freire-Maia N, Pinheiro M. Ectodermal dysplasia. A clinical and genetic study. New York: Alan R Liss, 1984:142-4.

3 Wiedemann HR. Cited in Freire-Maia N, Pinheiro $M$. Ectodermal dysplasia. A clinical and genetic study. New York: Alan R Liss, 1984:100-1.

Correspondence and requests for reprints to Dr $\mathrm{J}$ Zlotogora, Department of Human Genetics, Hadassah Medical Center, PO Box 12000, Jerusalem, Israel. 